\title{
The Seasonal Cycle of Sea Level in Sri Lanka and Southern India
}

\author{
E.M.S. Wijeratne ${ }^{1}$, P.L. Woodworth ${ }^{2}$ and V. N. Stepanov ${ }^{2}$ \\ ${ }^{\prime}$ National Aquatic Resources Research and Development Agency, Crow Island, Mattakkuliya, Colombo 15, Sri \\ Lanka; ${ }^{2}$ Proudman Oceanographic Laboratory, 6 Brownlow Street, Liverpool L3 5BX, United Kingdom
}

\begin{abstract}
Keywords: Sri Lanka tide gauge measurements, Indian Ocean seasonal circulation, Mean sea level variability, Indian Ocean seasonal altimeter measurements

Abstract-Mean sea level (MSL) data recorded at tide gauge stations in Sri Lanka and southern India, some previously unpublished, have been used in order to determine the main characteristics of the seasonal cycle of MSL in the region, concentrating on the annual component. Altimetric, meteorological and hydrographic information, together with results from numerical modelling, have been employed to try to understand the main factors which contribute to the observed MSL changes. Success in obtaining understanding has been relatively modest, especially for the southern Indian coastline, but proposals are put forward for further work in order to derive greater insight into the seasonal variability. With regard to Sri Lanka, it is evident that change in steric sea level (or dynamic height) is the main factor leading to seasonal MSL change. However, even in this case, there are apparent systematic differences between the various data sets, indicating scope for further research.
\end{abstract}

\section{INTRODUCTION}

This paper discusses the seasonal cycle of sea level around the coast of Sri Lanka and along the neighbouring coastline of southern India. The seasonal cycle in this area is larger than in many other parts of the Indian Ocean and requires explanation. This has been addressed with the use of new sea level data sets at two locations in Sri Lanka, together with historical tide gauge, altimetric, meteorological and hydrographic information from India and Sri Lanka and recently acquired numerical model data sets.

An understanding of the seasonal cycle of sea level forms an important component of climate studies. However, aside from scientific interest in the cycle, there are practical reasons for knowing as much about the spatial variations in the cycle as possible. The peak-to-peak range of the cycle is approximately $200 \mathrm{~mm}$ throughout most of the area, and is over $400 \mathrm{~mm}$ at some locations, which means that the cycle has practical importance in, for example, the production of accurate tidal prediction tables for the coastline.

Sea level variations have been studied for the Indian coastline by a number of authors. For example, secular trends in mean sea level (MSL) and extreme sea levels have been investigated by Unnikrishnan et al. (2004, 2006) and Unnikrishnan and Shankar (2007), while the difficulty of explaining the seasonal cycle in MSL has been described by Shankar (2000). However, there are few corresponding studies for Sri Lankan locations, and this paper represents one first such investigation.

\section{DATA SETS}

Most values of monthly MSL discussed in this paper have been obtained from the database of the 
Permanent Service for Mean Sea Level (PSMSL), which is described by Woodworth and Player (2003) and can be accessed at www.pol.ac.uk/psmsl. The historical MSL values for Indian locations have been reliably provided to the PSMSL for many years by the Geodetic and Research Branch of the Survey of India, while three separate data sets for Colombo, Sri Lanka were obtained by the PSMSL from the British Oceanographic Data Centre and the National Aquatic Resources Research and Development Agency (NARA) in Sri Lanka.

In recent years, NARA has made considerable efforts to construct a national sea level network. This development has been undertaken in collaboration with the University of Hawaii Sea Level Center (USA) and the Bundesamt für Seeschifffahrt und Hydrographie (Germany), with major upgrades taking place following the Sumatra tsunami of 2004. For the present paper use was made of seven and two station-years of MSL data from Karainagar and Trincomalee respectively. These data have not been published previously. Other sea level data are available from the Colombo and Kirinda stations in the new network (Figure 1, see also www.nara. ac.lk), although they are not as yet of adequate quality and quantity.

TOPEX/POSEIDON (T/P) radar altimeter data for cycles 1-364, representing almost a decade of 10-day cycles starting in 1992, were obtained from Archivage, Validation et Interprétation de données des Satellites Océanographiques (AVISO, 1994). Sea surface heights were determined at 'standard latitude points' corresponding to almost $6 \mathrm{~km}$ (or approximately 1 second) along-track, adjusted for ionospheric and atmospheric corrections together with sea state bias, solid earth tide, elastic ocean tide, geocentric pole tide and local inverse barometer air pressure corrections. Adjusted sea surface heights at each standard point were combined into monthly averages, with each monthly mean being defined by typically three sea surface height measurements. Further details of data processing are described by Andrew et al. (2006).

Monthly mean air pressure values were obtained from the HadSLP2 data set of the Hadley Centre, UK Met Office, see Allan and Ansell (2006) and hadobs.metoffice.com/hadslp2. This data set consists of a $5 \times 5$ degree global grid of monthly means covering the period 1850 onwards, from which we have chosen to use 1975-1989 to define an average seasonal cycle in air pressure for consistency with the barotropic model information mentioned below. Climatological monthly mean values of dynamic height were computed from the climatological monthly mean temperature and salinity fields of the World Ocean Atlas 2005 (WOA'05), as described by Boyer et al. (2006) and www.nodc.noaa.gov/OC5/WOA05/pr_woa05. html.

Sea level changes caused by ocean tides and changes in air pressure and winds were studied with a 0.25 degree global barotropic model. This model is a high resolution development of the 1-degree barotropic model which has been used previously (Hughes and Stepanov 2004; Stepanov and Hughes 2004) and is based on the Ocean Circulation and Climate Advanced Modelling Project (OCCAM) code (Webb et al. 1997). So far, the model has been driven by six-hourly air pressures and winds for the period 1975-1989 obtained from the European Centre for Medium-Range Weather Forecasts (ECMWF). While the increase in resolution provides a significant improvement for many studies, the spatial resolution is still a relatively coarse one when compared to the width of the Sri Lankan shelf (Figure 1 and see below). Nevertheless, it provides a means for assessing the importance of the role of winds in the sea level records and, in the present context, in the seasonal cycle of sea level. Monthly mean sea levels were computed from the modelled elevations in a similar way as if they had been tide gauge data.

\section{SEASONAL CYCLE OF THE INDIAN OCEAN AND SRI LANKA/SOUTHERN INDIA REGION}

Figure 2 presents the amplitudes and peak months of the annual component of the seasonal cycle of sea level for stations in the Indian Ocean. The annual parameters have been calculated by harmonic analysis using MSL values from years of data in the PSMSL data set which contain all 12 months of information. At least three such years are required. Year-to-year datum control is not essential for this computation (i.e. in PSMSL terminology the data 


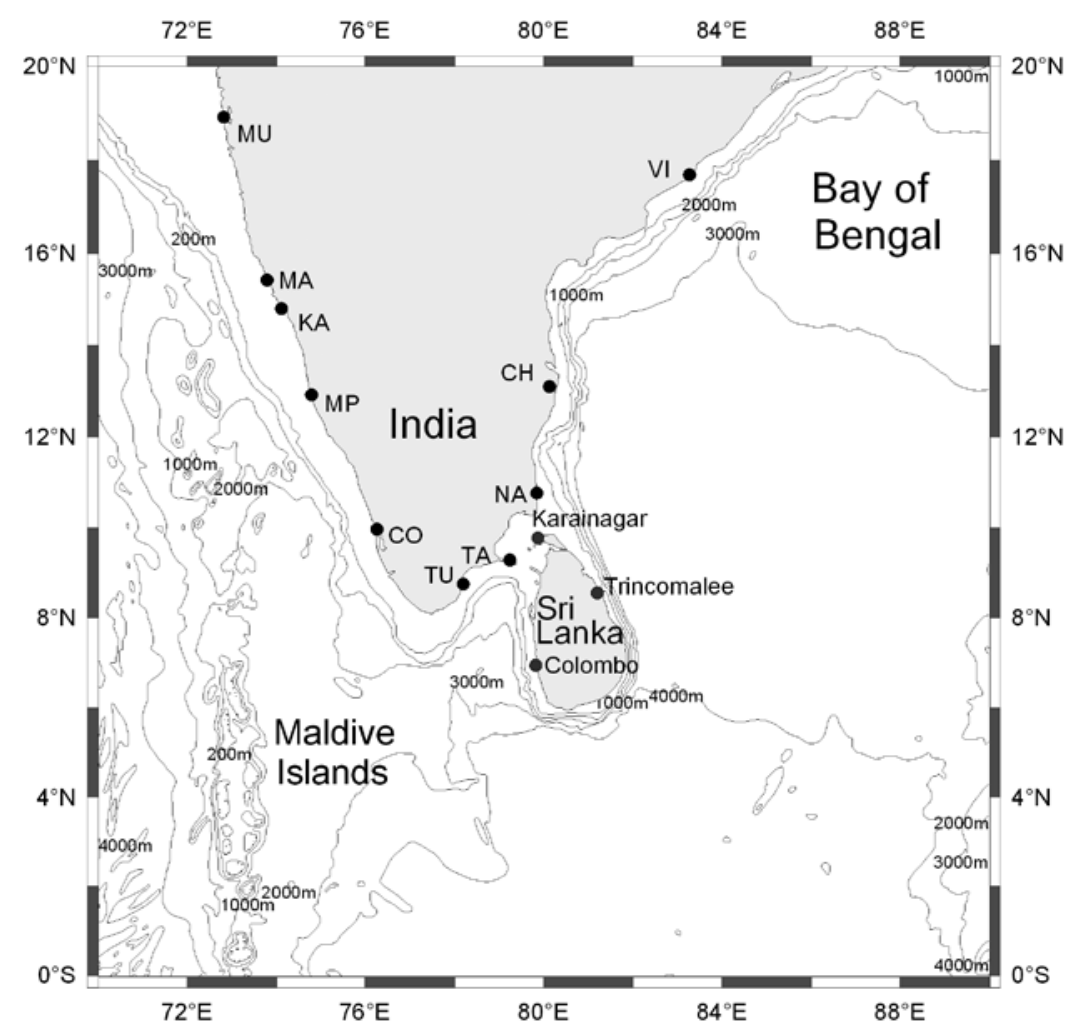

Fig. 1. Bathymetry of the waters around southern India and Sri Lanka with depths shown in metres and locations of the sea level stations with data discussed in the text: MU Mumbai, MA Marmagao, KA Karwar, MP Mangalore, CO Cochin, TU Tuticorin, TA Tangachchimadam, NA Nagappattinam, CH Chennai and VI Vishakhapatnam
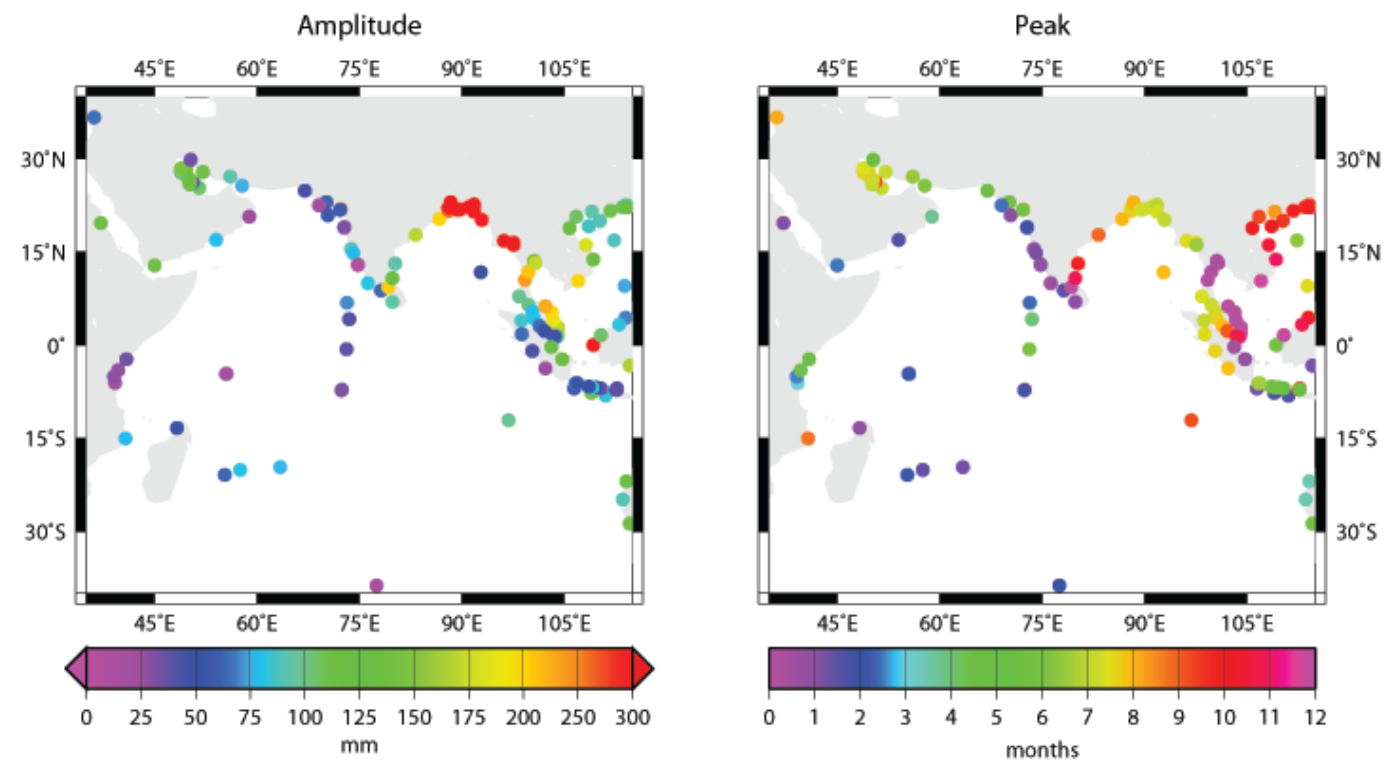

Fig. 2. Amplitude ( $\mathrm{mm}$ ) and peak month of the annual component of the seasonal cycle of sea level in the Indian Ocean computed from PSMSL data. (Note non-linear colour scale used for the largest amplitudes) 
need not be in its Revised Local Reference set). The method employed closely follows that used previously by Tsimplis and Woodworth (1994).

Amplitudes can be seen to be several 10s mm throughout the central-western Indian Ocean and along the west coast of India. These increase to $100-150 \mathrm{~mm}$ as one progresses around the south and up the east coast of India, until one reaches the very large amplitudes of the Ganges delta associated with large seasonal fluctuations in runoff. Amplitudes once again reduce as one travels along the coastlines of Burma and Thailand until one obtains values of the order of 50-100 mm once again in Malaysia and Indonesia.

Large differences are observed in the month at which the annual cycle peaks. In the western Indian Ocean and along the west coast of India, the cycle peaks at the start of the year or shortly afterwards. However, on the east coast of India the cycle peaks around October-November, with much earlier peaks on the northern and eastern sides of the Bay of Bengal. From the lone Sri Lanka value in Figure 2 (for Colombo, PSMSL country/station code 520/002), it appears that the cycles of the west coasts of both Sri Lanka and India are similar.

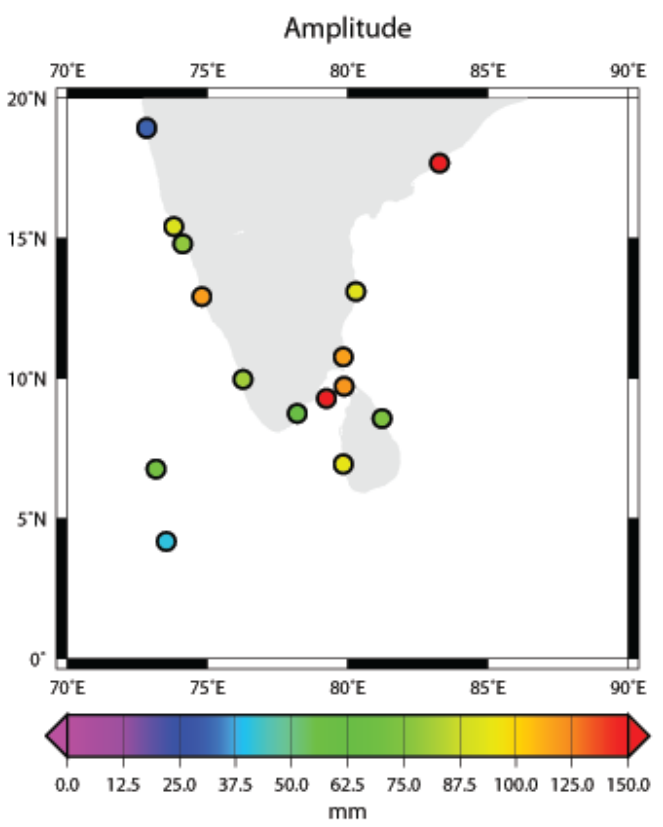

India provides an example of a country with different seasonal cycles on different coastlines. Thailand and Malaysia present particularly interesting examples and many other examples can be found around the world (see Tsimplis and Woodworth, 1994 and, most recently, Kang et al., 2008 for the Korean peninsula).

Figure 3 presents similar information but with a focus on Sri Lanka and southern India, with the new data from Karainagar and Trincomalee included, and with the three-year selection rule relaxed slightly to accommodate Trincomalee. Annual and semi-annual parameters for each site are shown in Table 1 together with an estimate of the uncertainty in the seasonal amplitudes based on the method of Wyrtki and Leslie (1980). The latter reflects how well the average seasonal cycle can be parameterised by an annual plus a semi-annual cycle (see also Woodworth, 1984 and Tsimplis and Woodworth, 1994). The amplitude of the annual cycle can be seen to increase from $20-30 \mathrm{~mm}$ at Mumbai (Bombay) to approximately $100 \mathrm{~mm}$ around most of the coast, with largest values at Tangachchimadam across the Palk Strait from Sri Lanka and at Vishakhapatnam on the north-east

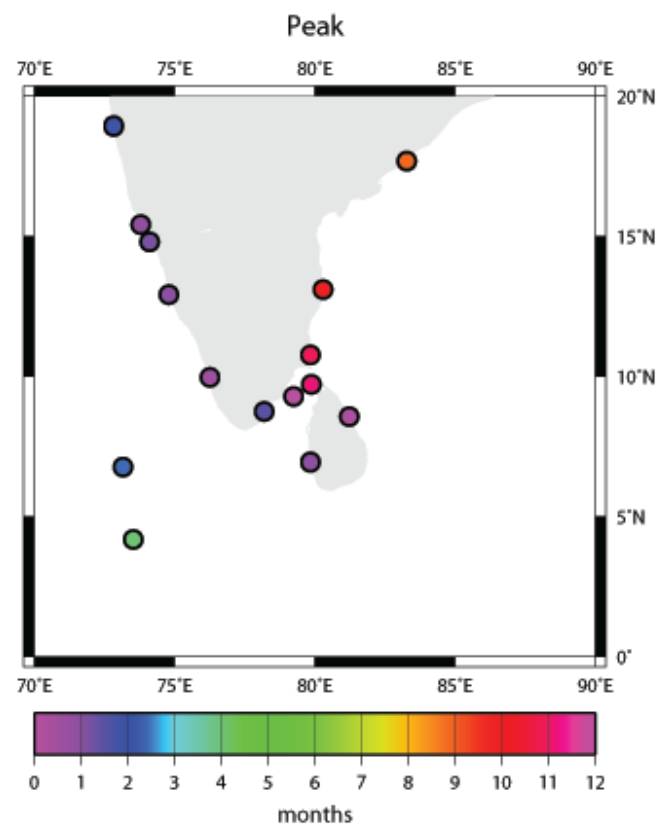

Fig. 3. Amplitude (mm) and peak month of the annual component of the seasonal cycle of sea level in Sri Lanka and southern India. (Note that the amplitudes are shown with a different colour scale to Figure 2) 


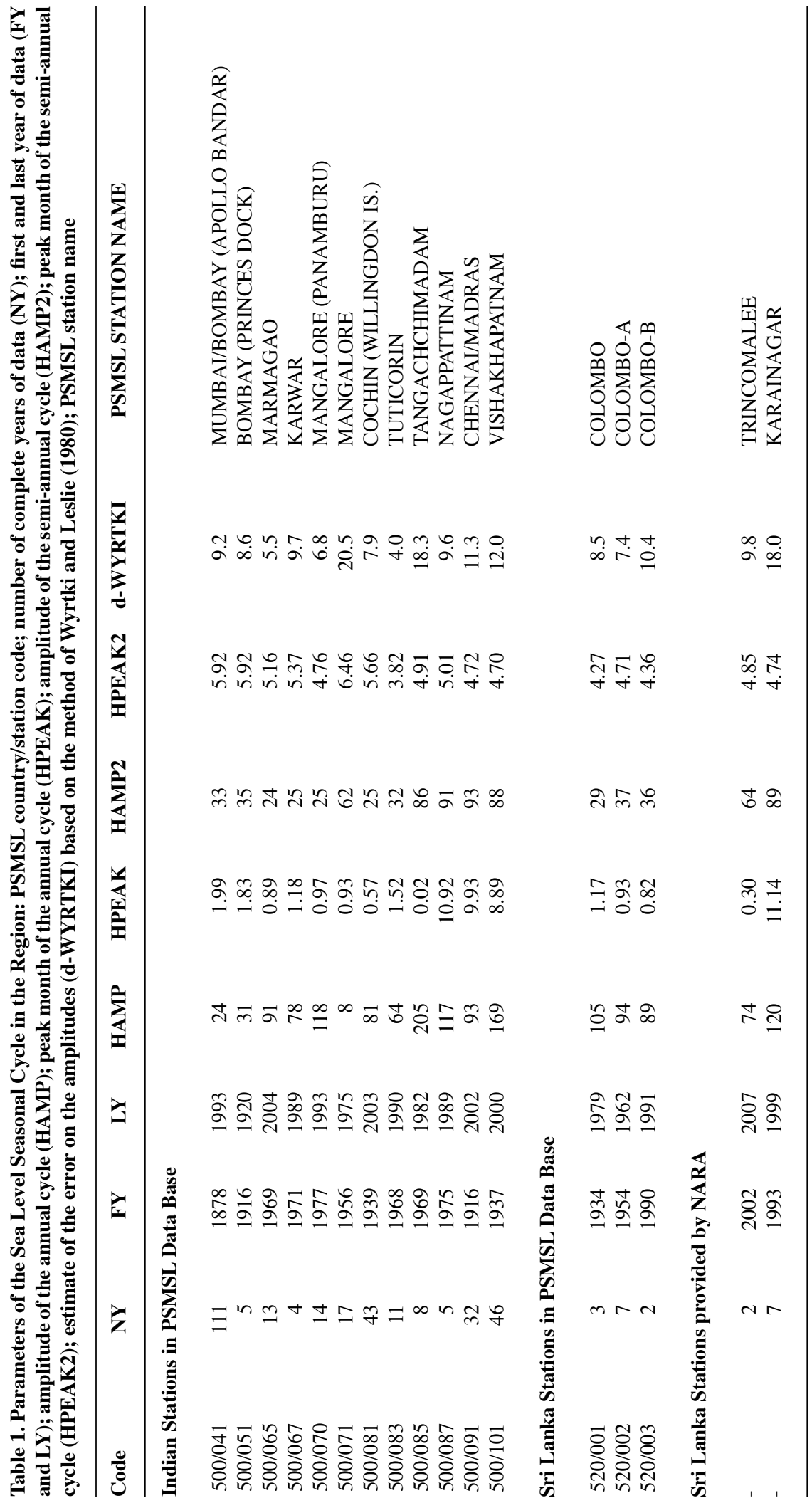


coast. The main outlier is the value from Mangalore (PSMSL country/station code 500/071) which has an annual cycle amplitude close to zero. In addition, Clarke and Liu (1994) found that the interannual variability in this, the older of the two Mangalore records, is inconsistent with the variability in other sea level records from the northern Indian Ocean. It seems that the estuary location of the earlier gauge provided a record that cannot be considered representative of the west Indian coastline. Therefore, it has not been included in Figure 3.

Of the new data at our disposal, the peak month of the annual cycle at Trincomalee on the east coast of Sri Lanka can be seen to be similar to that of the west coasts of both countries, while at Karainagar in the north of the island the peak is earlier, conforming more to the cycle of the east coast of India. The amplitude of the annual cycle at Karainagar is larger than at Trincomalee and Colombo, consistent with a progression towards the very large amplitudes observed at Tangachchimadam.

The uncertainty of the seasonal parameters was assessed in several ways. In one method, each record was divided into two and annual and semi-annual parameters were calculated for each set. The estimated standard error on the annual amplitude was calculated as $1 / \sqrt{ } 2$ of the vector difference between the two vectors defined by each annual amplitude and peak. A corresponding estimated standard error was calculated for the semi-annual amplitudes. Annual and semi-annual errors determined this way were of the order of 10 $\mathrm{mm}$ (a maximum of $14 \mathrm{~mm}$ at Colombo) consistent with the uncertainty from the Wyrtki and Leslie (1980) method. Uncertainties were investigated in greater detail for particular stations. For example, the high amplitude observed at Tangachchimadam deserved closer study. However, high amplitudes were indeed observed in both halves of its record with an estimated annual standard error of $9 \mathrm{~mm}$. As regards Sri Lanka, consistency of parameters was observed for the sub-sets of Colombo data (Table 1) and throughout the Karainagar record.

Figure 4 demonstrates the average seasonal cycle for stations on the west and east coasts of India and in Sri Lanka. The peak-to-peak range of the average cycle can be seen to be approximately $200 \mathrm{~mm}$ at most locations but to exceed $400 \mathrm{~mm}$ at some stations. The figure shows the greater consistency of phase of the cycle on the west coast of India, compared to the east coast, evident also in Table 1. In addition, it demonstrates clearly that at some locations the annual component does not provide a full description of the seasonal cycle, requiring the addition of at least a semi-annual term. In particular, one can see a short period of high MSL in November-December for the two Palk Strait stations (Tangachchimadam and Karainagar).

In most parts of the world, the amplitude of the semi-annual cycle is much smaller than the annual component (Tsimplis and Woodworth, 1994). However, Table 1 shows that around most of the southern Indian coastline, and on the north and east coasts of Sri Lanka, if less so on the west coast, the seasonal cycle is far from being describable by a simple 12 month (annual) term. The semi-annual component can be seen to have an amplitude comparable to that of the annual at several stations in the region (e.g. Bombay on the west coast of India; Nagappattinam and Chennai on the southeast coast; and Trincomalee and Karainagar in Sri Lanka), while for most of the west coast of India and Sri Lanka the amplitudes are in proportion about 3:1. In most cases in India, the semi-annual cycle peaks in May or June (and November and December), and in May for Sri Lanka.

In most of the following discussion of the contributing factors to the seasonal cycle, we concentrate on the annual component as that term is generally the larger and is most robustly identified in the available data sets.

\section{CONTRIBUTING FACTORS TO THE SEASONAL (PRIMARILY ANNUAL) CYCLE OF SEA LEVEL}

There are many factors which contribute to a seasonal cycle of sea level (e.g. Gill and Niiler, 1973; Pugh, 1987). These include:

1. Seasonal changes in the density of the water column ('steric changes') as represented in computations of dynamic height based on hydrographic data sets of temperature and salinity.

2. Air pressure changes through some approximation of the 'inverse barometer' model. 


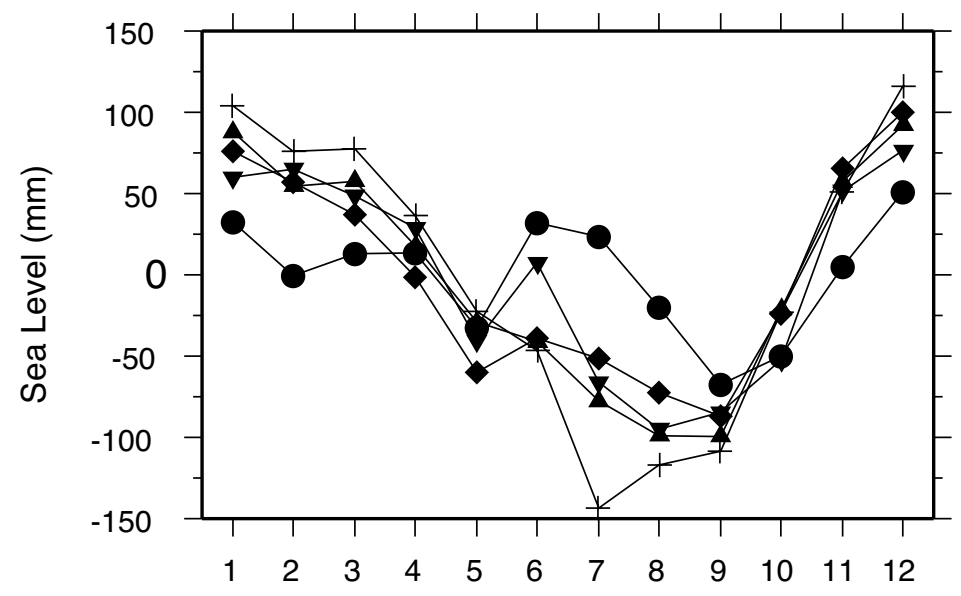

(a)

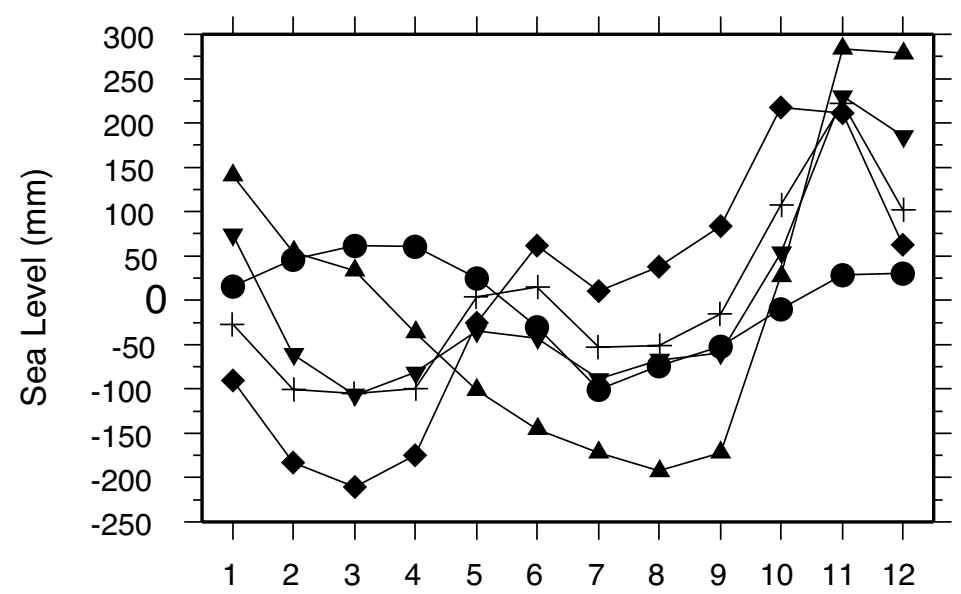

(b)

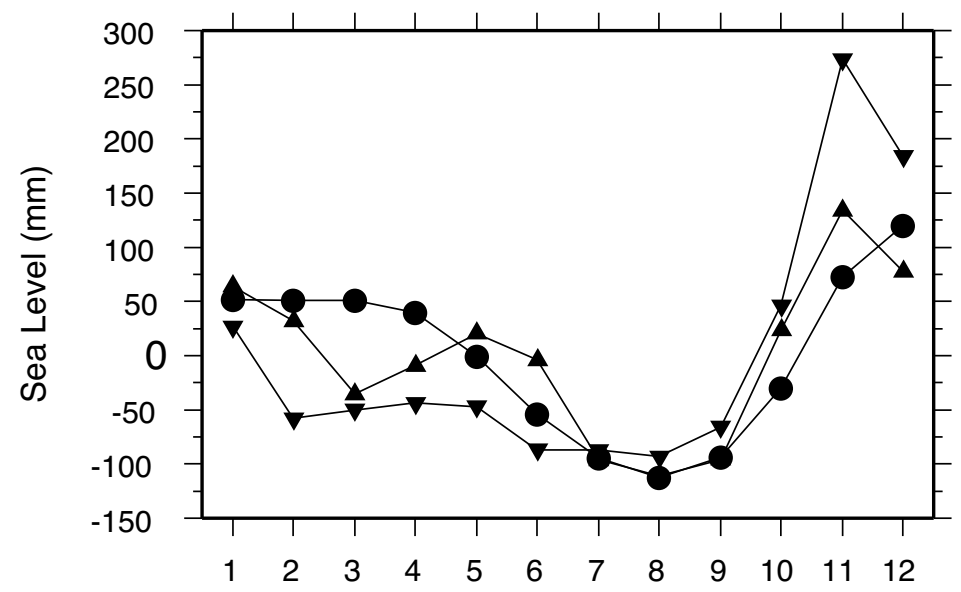

(c)

Fig. 4. (a) Average seasonal cycle of MSL at stations on the west coast of India: Mumbai (dot), Marmagoa (triangle), Karwar (inverted triangle), Mangalore Panamburu (cross) and Cochin (diamond); (b) at stations on the east coast of India: Tuticorin (dot), Tangachchimadam (triangle), Nagappattinam (inverted triangle), Chennai (cross) and Vishakhapatnam (diamond); (c) at stations in Sri Lanka: Colombo (dot), Trincomalee (triangle) and Karainagar (inverted triangle). For stations with more than one record (cf. Table 1), the average cycle for the longest record has been plotted 
3. Seasonal changes in the wind field which induce changes in ocean currents and wind setup in coastal areas. Wind setup is usually adequately described with the use of a depth-averaged model scheme.

4. Variations on seasonal timescales in river runoff.

5. Global seasonal changes of the mass of water in the ocean.

6. Long period astronomical tides.

A particular issue which has to be addressed is that, if one is to compare the observed MSL seasonal cycle to those of possible contributing factors, or even if one is to compare the MSL seasonal cycle at one station to that at another, then one can seldom have available information from the same years. For example, Table 1 shows that most of our MSL information was acquired from before T/P data became available, while hydrographic data from many individual locations and epochs will have gone into the production of the WOA'05. Consequently, an approximate yearto-year regularity of the seasonal cycle has to be assumed. Given that one knows that interannual and decadal variability exists throughout the world's oceans (and, in particular, in the Indian Ocean through El Niño Southern Oscillation (ENSO),

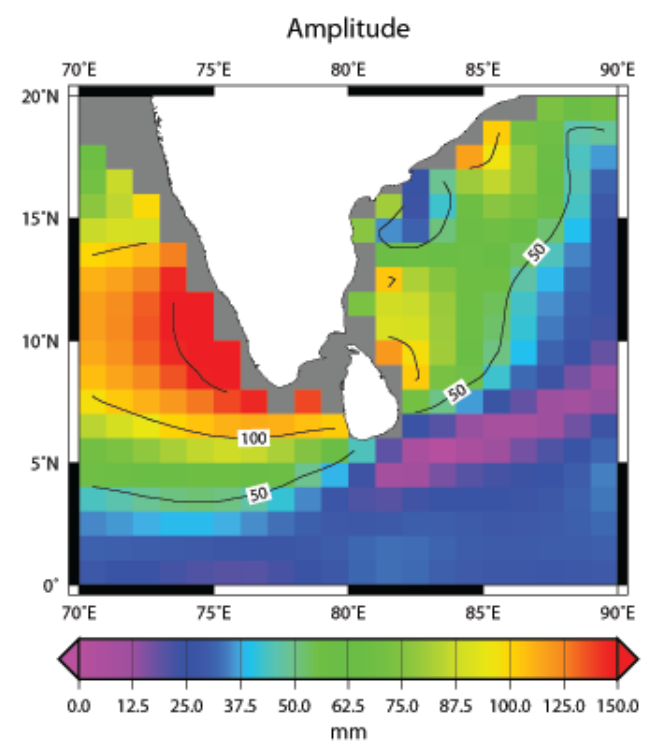

Indian Ocean Dipole (IOD) and other processes), then it is clear that some differences in seasonal characteristics are to be anticipated in any analysis. Tsimplis and Woodworth (1994) suggested that five years of data could be enough at many locations to establish an 'average seasonal cycle'. However, such an assertion remains to be confirmed in many areas with much longer data sets.

\section{Changes in Dynamic Height}

The annual component of the seasonal cycle in dynamic height relative to 1500 decibar $(1500 \mathrm{~m})$ in the area, computed from the one-degree monthly temperature and salinity fields of the WOA'05, is shown in Figure 5. The largest amplitude area, of the order of $100 \mathrm{~mm}$, extends from SW India to the east coast of Sri Lanka, with maximum values at the start of the year in high amplitude areas, and peak months towards the middle of the year off the east coast of India and in the deep waters of the SE of the region. The high amplitude region has been linked with the variations of the monsoon-current system south of Sri Lanka, and associated changes in the wind field, as discussed in some detail by Vinayachandran and Yamagata (1997), Shankar (2000), Schott and McCreary (2001) and Shankar et al. (2002).

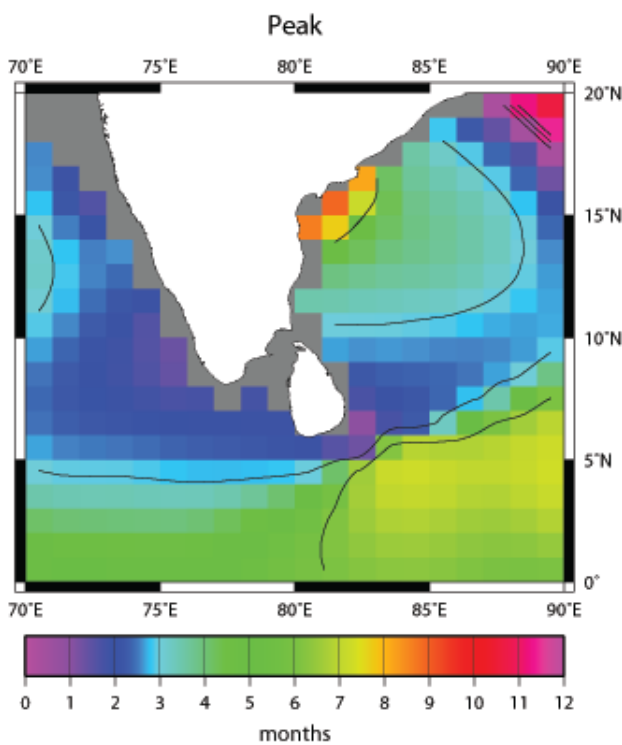

Fig. 5. Amplitude (mm) and peak month of the annual component of the seasonal cycle of dynamic height. Amplitudes are contoured every $50 \mathrm{~mm}$; peak month contours are at months 3, 6, 9 and 12 
In principle, one would like to extend the seasonal dynamic height computation to the coast as one knows that the coastal climatology should encompass known local processes such as upwelling during the summer monsoon (Vinayachandran $e t$ al., 2004). However, there are several problems in doing so. A practical one is that, by computing dynamic height relative to the ocean bottom where the water depth is less than $1500 \mathrm{~m}$, adds few extra grid boxes with WOA'05 information to Figure 5. However, even if more copious and higher-resolution data sets were available, there are more fundamental problems associated with the dynamical consistency of such information; we return to this issue below.

Confirmation of the general features of Figure 5 are obtained from analysis of $\mathrm{T} / \mathrm{P}$ altimeter data. Figure 6 describes the annual cycle of sea surface height (inverse barometer corrected) along altimeter ground tracks, indicating the high amplitude region to the SW of India, which on a larger map can be seen to extend in a band westwards towards Somalia, and lower amplitude in the south of the region (similar maps have recently been presented by Vinogradov et al., 2008). In contrast to Figure 5 , relatively high amplitudes are observed in parts of the SW Bay of Bengal. The peak month of the annual cycle obtained from altimetry occurs in the early part of the year along the entire west coast of India, while the peak month occurs much later in the year in the northern Bay of Bengal (and also along eastern coasts of the Bay as can be seen on a larger map). The altimetric patterns show many similarities to those from the WOA'05 climatology. Together these fields suggest that the annual signal in dynamic height is a first-order contributor to that of sea level in Sri Lanka and southern India.

\section{Air Pressure (and Inverse Barometer Sea Level) Changes}

Air pressure changes can contribute to sea level change through some approximation of the 'inverse barometer' (IB). These are clearly of greatest importance at mid- and high-latitudes, where seasonal variability in air pressure is greatest, but also must be taken into consideration in the tropics (Mathers and Woodworth, 2001). In the present study, air pressure changes have been investigated with the use of the HadSLP2 data set. The parameters of the annual component of the seasonal cycle averaged over 1975-1989 at
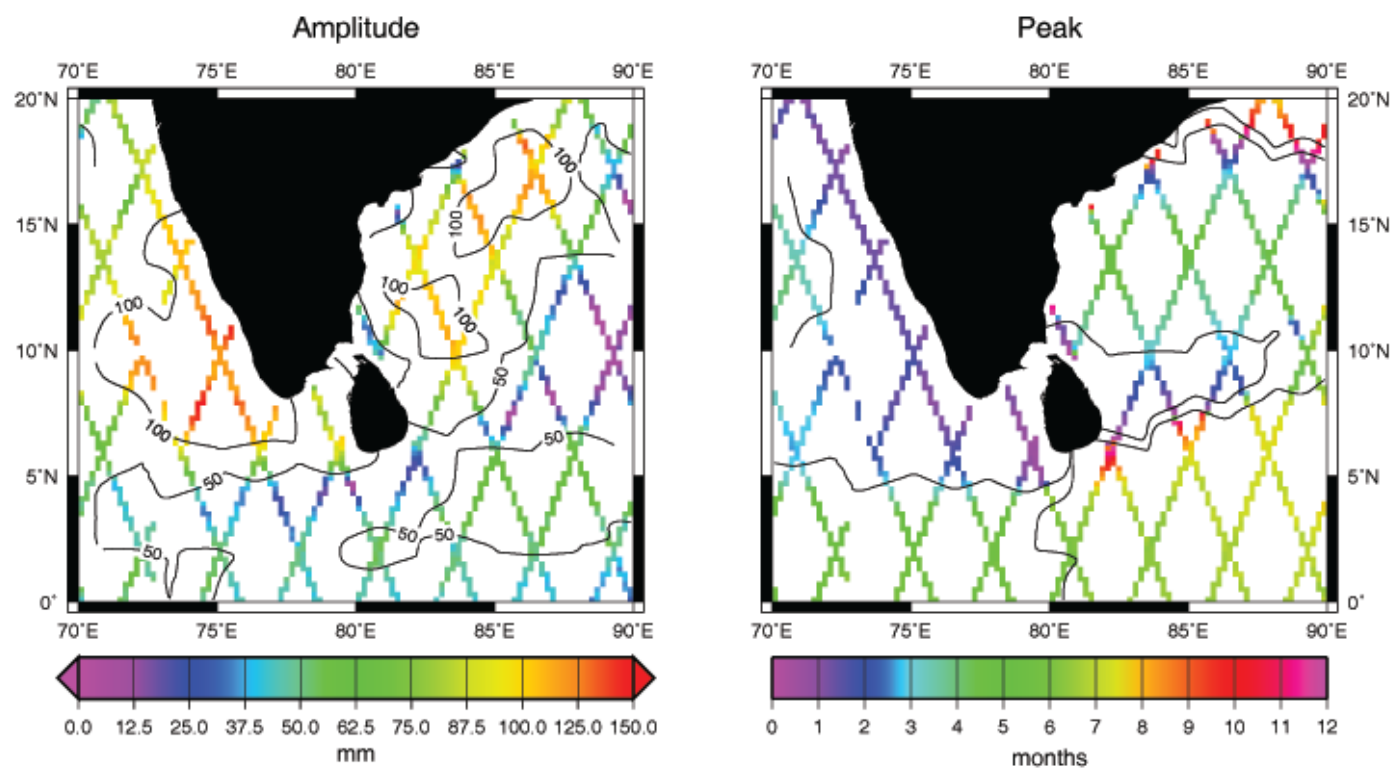

Fig. 6. Amplitude (mm) and peak month of the annual component of sea level (adjusted for air pressure assuming an inverse barometer relationship) from TOPEX/POSEIDON altimeter data. Contours have been drawn by spatial smoothing between altimeter ground tracks and should be considered as approximate. Amplitudes are contoured every $50 \mathrm{~mm}$; peak month contours are at months $3,6,9$ and 12 
the longitudes of southern India and Sri Lanka are typically amplitude $9 \mathrm{~mm}$ and peak month 5.6 at $5^{\circ} \mathrm{N}$, increasing to amplitude $68 \mathrm{~mm}$ and peak month 6.2 at $20^{\circ} \mathrm{N}$. The peak month values given here are 'inverted' to correspond to the peak month of sea level change, if an approximate IB relationship was to apply. (Amplitudes are slightly higher on the east coast of India than the west coast at the same latitude. A small correction with an amplitude of approximately 0.6 mbar should in principle be made to account for changes in air pressure over the global ocean: Dorandeu and Le Traon, 1999. That is automatically accounted for in the numerical model described below.) Amplitudes are consequently comparable to the estimated standard error on the annual amplitude of sea level at $5^{\circ} \mathrm{N}$ but increase with latitude.

\section{Changes in Sea Level due to Air Pressure and Winds}

The contributions made by air pressure and winds have been studied by means of the global barotropic ocean model mentioned above. This model can describe the barotropic changes of the deep ocean (e.g. Hughes and Stepanov, 2004) and can simulate to some extent the tide and surge variability on the continental shelves. However, before discussing model findings, it is useful first to consider the bathymetry of the region (Figure 1). Sri Lanka has a narrower $(2.5-25 \mathrm{~km})$ and shallower $(30-90 \mathrm{~m})$ shelf than most parts of the world coastline (typically 75 $125 \mathrm{~m}$ ). The shelf is narrowest around the southern part of the island and broadens to merge with the Indian continental shelf towards the north and northeast. The outer edge of the shelf falls steeply to between $3,000-4,000 \mathrm{~m}$. It is clear that the 0.25 degree resolution of the barotropic model will be of only qualitative value in this area in its ability to simulate changes due to tide and surge. The southern Indian continental shelf is wider than that of Sri Lanka, and broadens towards the north. The predictions of the model are expected to be more reliable for these areas.

The model has been used to determine seasonal cycle parameters for the period 1975-1989. Figure 7 shows the amplitude of the annual cycle which peaks around month 6 as suggested by the IB relationship. This phase remains essentially the same even for the shelf area in the NW of the region where the surge contribution increases the amplitude to approximately $100 \mathrm{~mm}$. It can be seen that this component must be a major contributor to the overall annual cycle, and comparable to the dynamic height signal, in the north of the region. However, this component peaks in the middle of the year, unlike sea level as observed in the area, and so it cannot be the dominant contributor.

The semi-annual amplitude of the barotropic signal is only a few millimetres throughout the region, except for the continental shelf area in the $\mathrm{NW}$ of the region where it increases to $10 \mathrm{~mm}$.

\section{River Runoff Effects}

The contributions of Sri Lanka river discharges to the regional hydrography is very low, the maximum being less than $0.004 \mathrm{~Sv}$ during July-August (1 Sv $=10^{6} \mathrm{~m}^{3}$ per second, a unit of volume transport, or Sverdrup). This is to be compared to the freshwater input to the Bay of Bengal, mainly from the Ganges, Brahmaputra and Irrawaddy rivers, of about 0.05 $\mathrm{Sv}$ averaged over the year $\left(1500 \mathrm{~km}^{3}\right.$ per year), and a maximum from the Indian rivers during the South-West Monsoon in August-September of approximately $0.09 \mathrm{~Sv}$, decreasing to about 0.076 $\mathrm{Sv}$ in November-December (Barua, 1990; Lopez and Kantha, 2000). For comparison, the total freshwater input to the Arabian Sea is only $190 \mathrm{~km}^{3}$ per year (Delaygue et al., 2001). In the absence of large rivers in Sri Lanka, and given that Sri Lankan tide gauges are sited away from probable major freshwater influences, then the river runoff effects on the sea level seasonal cycle are considered small. There is less confidence in making such a statement with regard to Indian tide gauge data. However, given that there are more tide gauges, one test for anomalous local influences is the check for consistency of information along the coastline (cf. comments on the Mangalore record above).

\section{Changes in Global Ocean Mass}

In addition to baroclinic changes of sea level which can be calculated from the information in hydrographic data bases, a component of the seasonal cycle of sea level will stem from the regular exchanges of water between hydrosphere, 


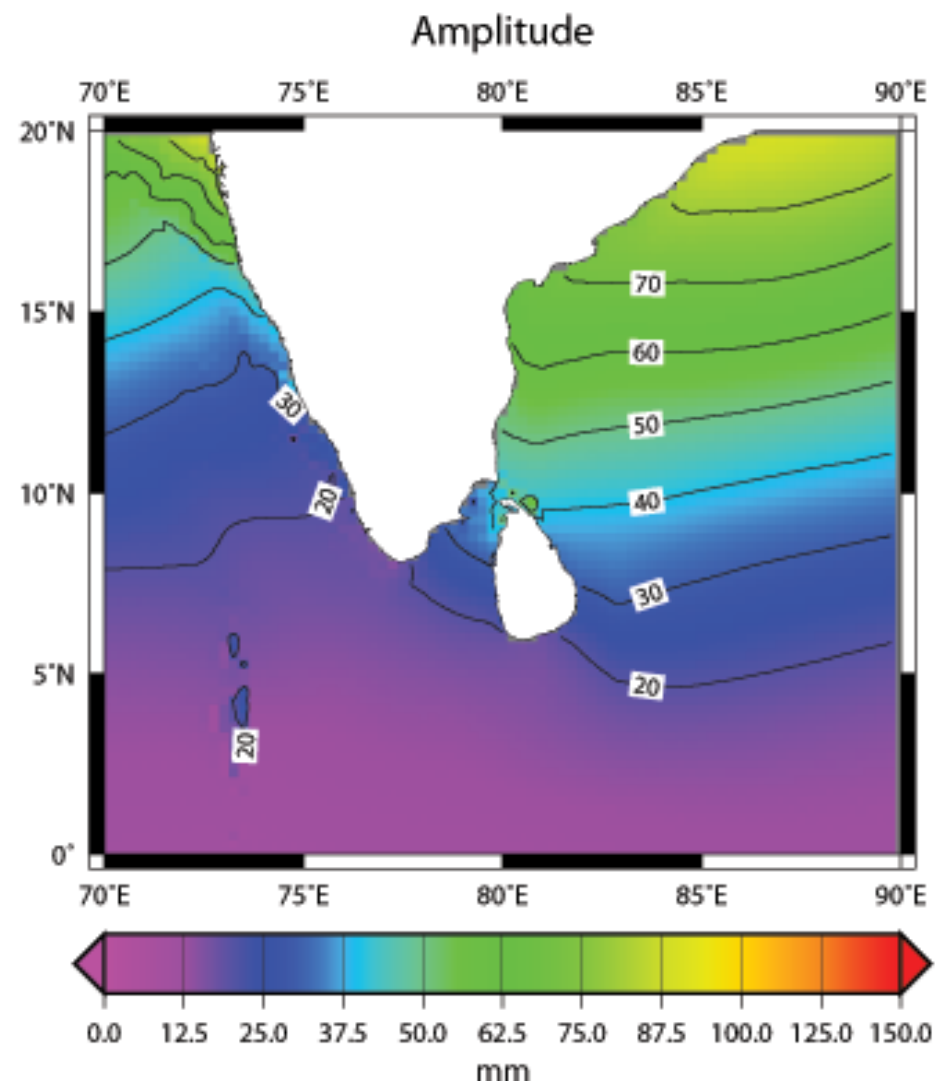

Fig. 7. Amplitude (mm) of the annual component of the seasonal cycle of sea level arising from barotropic sea level changes due to changes in air pressures and winds. Amplitudes are contoured every $10 \mathrm{~mm}$

cryosphere and ocean resulting in seasonal redistribution of ocean mass (e.g. Minster et al., 1999). One method of estimating this signal is with the use of Global Positioning System (GPS) receivers to study seasonal changes in the oceanic loading of the solid Earth (Blewitt and Clarke, 2003; Clarke et al., 2005). From such studies one can estimate an annual sea level signal in the area in question with amplitude of at least $11 \mathrm{~mm}$ with a maximum in late January (based on parameters in Table 4 of Blewitt and Clarke (2003) and P.J. Clarke, pers. comm.). In principle, a similar signal can be inferred from temporal space gravity measurements. Ponte et al. (2007) concluded that global-average signals in ocean bottom pressure (akin to ocean mass) are similar to those determined from GPS loading measurements (i.e. of order 10 $\mathrm{mm}$ amplitude). In the northern Indian Ocean in the area of Sri Lanka, the annual signal in bottom pressure, determined from two analyses of Gravity
Recovery And Climate Experiment (GRACE) data and one from an ocean modelling study, was also found to be about $10 \mathrm{~mm}$ in amplitude. However, the determination of peak month differed considerably between the three studies. Overall, from the GPS and space gravity estimates, and from the similarity in the magnitude of the annual cycle from hydrography and altimetry in Figures 5 and 6 , it can be concluded that only approximately $10 \%$ of the seasonal sea level cycle along the Sri Lanka coast may be explainable by such changes in ocean mass.

\section{Astronomical Tides}

The amplitudes of the annual and semi-annual astronomical tides in the ocean are approximately 1 and $7 \mathrm{~mm}$ at the equator and decrease with latitude (Pugh, 1987), and in practice are below the levels of uncertainty in properly describing the larger, 
meteorological and other factors. The annual term can even be complicated by the presence of a small 12 month component of the pole tide (Vondrák, 1988).

\section{SYNTHESIS AND DISCUSSION}

In principle, the observed seasonal cycle of sea level in the southern India and Sri Lanka region (Table 1) should be attributable to the various contributing factors described above, concentrating once again on the main (annual) component. As a first approximation, the global ocean mass and astronomical tidal factors might be disregarded as they will contribute little more than $10 \mathrm{~mm}$. Runoff effects may also be disregarded as they will include primarily local (and largely unquantifiable) signals, or, where runoff is so large as to impact upon the hydrography of the open ocean, then it should be represented in the dynamic height calculations. That leaves the steric (ocean density) effects, represented by the dynamic height calculations, together with the barotropic sea level processes, with which to explain the observed sea level changes.

At a qualitative level, there is some similarity between observations and the two main contributing factors. One may consider three regions: (i) the south of India and Sri Lanka, (ii) the west coast of India, and (iii) the east coast of India.

For (i), one might even disregard barotropic (largely IB) changes also because of their small amplitude (Figure 7). One sees from Figure 5 that in the nearby deep ocean annual steric (dynamic height) amplitudes are between 100-150 mm, peaking around the end of February. On the NE coast of Sri Lanka (cf. Trincomalee), the steric amplitude is a little lower, and peaks about one month later, than on the west coasts of India and Sri Lanka. This lower amplitude is consistent with the measurements of Table 1, although Trincomalee peak month in Table 1 is slightly earlier than at Colombo. Overall, the steric annual cycle peaks 1-2 months later than the sea level annual cycle.

As regards (ii), one might combine an annual steric signal of the order of $100-150 \mathrm{~mm}$, peaking around February, with a barotropic signal of approximately $50 \mathrm{~mm}$, peaking at the start of July. Therefore, the two processes to some extent have an opposite phase and a lower overall amplitude results than is the case for (iii). In this case, the steric amplitude is smaller than for the west coast, but peaks in the middle of the year at approximately the same time as a slightly larger barotropic component than for the same latitude on the west coast.

However, it must be admitted that this qualitative explanation is far from complete or satisfactory. Table 1 shows amplitudes to vary around the coastline of India to a greater extent than is capable of explanation by the long-wavelength processes described in Figures 5 and 7. Part of this inconsistency may be due to the fact that we have been forced to employ a non-contemporaneous set of sea level and contributing factor information, as explained above. However, an additional consideration is indicated by the high amplitudes at Tangachchimadam and Karainagar on the Indian and Sri Lankan sides respectively of the shallow Palk Strait. Such local variations will not be describable in terms of the data sets at our disposal.

Amongst previous investigations of this region, Han and Webster (2002) described a modelling study of inter-annual sea level variability in the Bay of Bengal and its relationship to ocean circulation variations and to local and distant forcings including runoff from the great rivers. A section of the paper gave a model description of the (inverse barometer corrected) climatological average sea level seasonal cycle (Han and Webster (2002), Figure 6) which appears to peak slightly later than observed in the area around Sri Lanka, as shown in Figures 3 and 5 of the present study.

Another extended discussion of the seasonal cycle of MSL in the region is that of Shankar (2000), based on the work of Shankar (1998). He provided examples of observed and 'corrected' (for the IB) MSL cycles and pointed to the importance of seasonal changes in along-shore winds, which are in turn associated with variations in the large-scale wind field, and the fluctuations in coastal currents which result and are associated with processes such as upwelling that should, in principle, be reflected in coastal dynamic heights. He successfully related shift-drift data, as a proxy for coastal current measurements, to the sea level seasonal cycles at various stations (except for Colombo and with some discrepancies in timings). However, he was not as successful in applying results from a numerical 
model forced by along-shore wind information. The difficulty with such coastal modelling, alluded to above, is that it has to be both inclusive and dynamically consistent. Such studies require a highresolution and complete 3-dimensional numerical model tuned to the hydrographic conditions of the coastal area (e.g. Young and Holt, 2007). Such modelling has yet to be performed for this region. Shankar (2000) furthermore speculated on the role of runoff from the great rivers of the northern Bay of Bengal and freshwater plumes that result. However, such large-scale processes should have been included in the hydrographic climatology discussed above.

\section{CONCLUSIONS}

The present analysis has endeavoured to use historical MSL data for India, and recent information from Sri Lanka, to understand further the general properties of the seasonal cycle of MSL in the region, concentrating on the annual component.

Annual amplitudes tend to be larger on the east coast of India (largest values 205 and 169 $\mathrm{mm}$ at Tangachchimadam and Vishakhapatnam respectively) than on the west coast (most amplitudes lower than $100 \mathrm{~mm}$ ). The annual cycle tends to peak in January on the west coast and two months earlier on the east coast. The semi-annual component has comparable amplitude to the annual term at a number of stations, and peaks in May-June around the Indian coast, and May in Sri Lanka. As regards Sri Lanka in particular, the annual cycle at Colombo has an amplitude and peak similar to stations on the west coast of India. The annual cycle peaks at Trincomalee on the east coast at a similar time to the west coasts of both India and Sri Lanka, while the peak at Karainagar is earlier, similar to stations on the east coast of India. The Trincomalee annual cycle has a smaller amplitude than at Colombo. The amplitude of the annual cycle at Karainagar is larger than both Trincomalee and Colombo, consistent with the large amplitude observed at Tangachchimadam across the Palk Strait.

We have had only modest success in explaining the annual cycle for the Indian coastline in terms of available data sets. While we have had a larger database at our disposal than Shankar (2000) employed, the missing factor in our opinion (as was recognised by Shankar) is an adequate set of coastal modelling in order to simulate the main coastal processes which lead to sea level change. This remark also applies to the Sri Lankan coastline. However, in this location, where the continental shelf is narrow, the observed annual cycle is explainable at least to first order by the dominant steric component recorded in the nearby deep ocean, with the amplitude on the east coast (e.g. Trincomalee) lower than that of the west coast. Nevertheless, the steric term seems to peak consistently one month or so later than the observed sea level, perhaps indicating the need for improved coastal modelling in this area also.

The amount of new sea level data from Sri Lanka that was included in this study is small but great efforts were made to acquire it and it is important to recognise its value. One way of doing that is by demonstrating the uses to which it can be put. The present analysis has attempted to demonstrate that the seasonal cycle is both large, and therefore of potential practical importance with regard to sea level prediction, and interesting with regard to a proper understanding of large-scale and coastal processes. The Sri Lankan data sets available for research will increase in size if existing stations are maintained and new ones added, and if all are shown to be useful. Plans are in place for further stations, starting with Talaimannar in the north-west of the island, which with stations on the Indian coast will provide information on flows through Palk Strait. It will be equipped with satellite transmission equipment for real-time monitoring as part of the Global Sea Level Observing System and Indian Ocean Tsunami Warning System.

Acknowledgements-This study was completed while E.M.S. Wijeratne was a visitor at the Proudman Oceanographic Laboratory through an Indian Ocean Tsunami Warning System Fellowship from the Intergovernmental Oceanographic Commission. Prof. Peter Clarke (Newcastle University), Drs. D. Shankar and A.S. Unnikrishnan (National Institute of Oceanography, India) and Drs. Chris Wilson and David Pugh (POL) are thanked for their advice. Some of the figures in this paper were generated using the Generic Mapping Tools (Wessel and Smith, 1998). 


\section{REFERENCES}

Allan, R. and Ansell, T. 2006. A new globally complete monthly historical mean sea level pressure data set (HadSLP2): 1850-2004. Journal of Climate, 19(22), 5816-5842.

Andrew, J.A.M., Leach, H. and Woodworth, P.L. 2006. The relationships between tropical Atlantic sea level variability and major climate indices. Ocean Dynamics, 56(5-6), 452-463, doi:10.1007/ s10236-006-0068-z.

AVISO. 1994. AVISO user handbook: merged TOPEX/ POSEIDON products. AVISO report AVI-NT-02101-CN, Edition 2.1. 213pp.

Barua, D.K. 1990. Suspended sediment movement in the estuary of the Ganges- Brahmaputra- Meghna river system. Marine Geology, 91, 243-253.

Blewitt, G. and Clarke, P. 2003. Inversion of Earth's changing shape to weigh sea level in static equilibrium with surface mass redistribution. Journal of Geophysical Research, 108 (B6), 2311, doi:10.1029/2002JB002290.

Boyer, T.P., Antonov, J.I., Garcia, H.E., Johnson, D.R., Locarnini, R.A., Mishonov, A.V., Pitcher, M.T., Baranova, O.K. and Smolyar, I.V. 2006. World Ocean Database 2005. S. Levitus, Ed., NOAA Atlas NESDIS 60, U.S. Government Printing Office, Washington, D.C., 190 pp., DVDs.

Clarke, A.J. and Liu, X. 1994. Interannual sea level in the northern and eastern Indian Ocean. Journal of Physical Oceanography, 24, 1224-1235.

Clarke P. J., Lavallée, D.A., Blewitt, G., van Dam, T.M. and Wahr, J.M. 2005. Effect of gravitational consistency and mass conservation on seasonal surface mass loading models. Geophysical Research Letters, 32, L08306, doi:10.1029/2005GL022441.

Delaygue, G., Bard, E., Rollion, C., Jouzel, J., Stievenard, M., Duplessy, J.C. and Ganssen, G. 2001. Oxygen isotope/salinity relationship in the northern Indian Ocean. Journal of Geophysical Research, 106, 4565-4574.

Dorandeu, J. and Le Traon, P.Y. 1999. Effects of global mean atmospheric pressure variations on mean sea level changes from TOPEX/Poseidon. Journal of Atmospheric and Oceanic Technology, 16, 12791283. doi: $10.1175 / 1520-0426$.

Gill, A.E. and Niiler, P.P. 1973. The theory of the seasonal variability in the ocean. Deep-Sea Research, 20, 141-177.

Han, W. and Webster, P.J. 2002. Forcing mechanisms of sea-level interannual variability in the Bay of Bengal. Journal of Physical Oceanography, 32, 216-239.
Hughes, C.W. and Stepanov, V.N. 2004. Ocean dynamics associated with rapid J2 fluctuations: Importance of circumpolar modes and identification of a coherent Arctic mode. Journal of Geophysical Research, 109, C06002, doi:10.1029/2003JC002176.

Kang S.K., Cherniawsky, J.Y., Foreman, M.G.G., So, J-K. and Lee, S.R. 2008. Spatial variability in annual sea level variations around the Korean peninsula. Geophysical Research Letters, 35, L03603, doi:10.1029/2007GL032527.

Lopez, J.W. and Kantha, L.H. 2000. A data-assimilative numerical model of the northern Indian Ocean. Journal of Atmospheric and Oceanic Technology, 17, 1525-1540.

Mathers, E.L. and Woodworth, P.L. 2001. Departures from the local inverse barometer model observed in altimeter and tide gauge data and in a global barotropic numerical model. Journal of Geophysical Research, 106(C4), 6957-6972, doi:10.1029/2000JC000241.

Minster, J.F., Cazenave, A., Serafinic, Y.V., Mercier, F., Gennero, M.C. and Rogel, P. 1999. Annual cycle in mean sea level from Topex/Poseidon and ERS-1: inference on the global hydrological cycle. Global and Planetary Change, 20, 57-66. doi:10.1016/ S0921-8181(98)00058-7.

Ponte R.M., Quinn, K.J., Wunsch, C. and Heimbach, P. 2007. A comparison of model and GRACE estimates of the large-scale seasonal cycle in ocean bottom pressure. Geophysical Research Letters, 34, L09603, doi:10.1029/2007GL029599.

Pugh, D.T. 1987. Tides, surges and mean sea-level: a handbook for engineers and scientists. Wiley, Chichester, 472pp.

Schott, F.A. and McCreary, J.P. 2001. The monsoon circulation of the Indian Ocean. Progress in Oceanography, 51, 1-123.

Shankar, D. 1998. Low-frequency variability of sea level along the coast of India. Ph.D. thesis, University of Goa, India. Available from http:// hdl.handle.net/2264/24.

Shankar, D. 2000. Seasonal cycle of sea level and currents along the coast of India. Current Science, 78, 279-288.

Shankar, D., Vinayachandran, P.N. and Unnikrishnan, A.S. 2002. The monsoon currents in the north Indian Ocean. Progress in Oceanography, 52, 63-120.

Stepanov, V.N. and Hughes, C.W. 2004. The parameterization of ocean self-attraction and loading in numerical models of the ocean circulation. Journal of Geophysical Research, 109, C03037, doi:10.1029/2003JC002034.

Tsimplis, M.N. and Woodworth, P.L. 1994. The global distribution of the seasonal sea level cycle 
calculated from coastal tide gauge data. Journal of Geophysical Research, 99(C8), 16031-16039.

Unnikrishnan A. S., Sundar, D. and Blackman, D. 2004. Analysis of extreme sea level along the east coast of India. Journal of Geophysical Research, 109, C06023, doi:10.1029/2003JC002217.

Unnikrishnan, A.S., Rupa Kumar, K., Fernandes, S.E., Michael, G.S. and Patwardhan, S.K. 2006. Sea level changes along the Indian coast: observations and projections. Current Science, 90, 362-368.

Unnikrishnan, A.S. and Shankar, D. 2007. Are sealevel-rise trends along the coasts of the north Indian Ocean consistent with global estimates? Global and Planetary Change, 57, 301-307. doi:10.1016/j.gloplacha.2006.11.029

Vinayachandran, P.N. and Yamagata, T. 1997. Monsoon response of the sea around Sri Lanka: generation of thermal domes and anticyclonic vortices. Journal of Physical Oceanography, 28, 1946-1960.

Vinayachandran, P.N., Chauhan, P., Mohan, M. and Nayak, S. 2004. Biological response of the sea around Sri Lanka to summer monsoon. Geophysical Research Letters, 31, L01302, doi:10.1029/2003GL0185333.

Vinogradov, S.V., Ponte, R.M., Heimbach, P. and Wunsch, C. 2008. The mean seasonal cycle in sea level estimated from a data-constrained general circulation model.Journal of Geophysical Research, 113, C03032, doi:10.1029/2007JC004496.
Vondrák, J. 1988. Is Chandler frequency constant? pp.359-364 in, The Earth's Rotation and Reference Frames for Geodesy and Geodynamics (eds. A.K. Babcock and G.A. Wilkins). Norwell, Mass.: Kluwer Academic.

Webb, D.J., Coward, A.C., de Cuevas, B.A. and Gwilliam, C.S. 1997. A multiprocessor ocean general circulation model using message passing. Journal of Atmospheric and Oceanic Technology, 14, 175-182.

Wessel, P. and Smith, W.H.F. 1998. New, improved version of Generic Mapping Tools released. EOS, Transactions of the American Geophysical Union 79, 579.

Woodworth, P.L. 1984. The worldwide distribution of the seasonal cycle of mean sea level. Institute of Oceanographic Sciences, Report No.190, 94pp. Institute of Oceanographic Sciences, Bidston, UK.

Woodworth, P. L. and Player, R.J. 2003. The Permanent Service for Mean Sea Level: an update to the 21st Century. Journal of Coastal Research, 19(2), 287-295.

Wyrtki, K. and Leslie, W.G. 1980. The mean annual variation of sea level in the Pacific Ocean. Hawaii Institute of Geophysics, Report HIG-80-5, $159 \mathrm{pp}$.

Young, E.F. and Holt, J.T. 2007. Prediction and analysis of long-term variability of temperature and salinity in the Irish Sea. Journal of Geophysical Research, 112, C01008, doi:10.1029/2005JC003386. 
